\title{
Health-related quality among life of employees with persistent nonspecific indoor-air-associated health complaints
}

\author{
Sanna Selinheimo ${ }^{\mathrm{a}, \mathrm{b}, \mathrm{c}, *}$, Aki Vuokko ${ }^{\mathrm{a}}$, Christer Hublin ${ }^{\mathrm{a}}$, Heli Järnefelt ${ }^{\mathrm{a}}$, Kirsi Karvala ${ }^{\mathrm{a}}$, \\ Markku Sainio $^{\mathrm{a}}$, Hille Suojalehto ${ }^{\mathrm{a}}$, Jaana Suvisaari ${ }^{\mathrm{b}}$, Tiina Paunio ${ }^{\mathrm{a}, \mathrm{b}, \mathrm{d}, *}$ \\ ${ }^{a}$ Finnish Institute of Occupational Health, Helsinki, Finland \\ ${ }^{\mathrm{b}}$ Department of Health, National Institute for Health and Welfare, Finland \\ ${ }^{\mathrm{c}}$ Department of Psychology and Logopedics, University of Helsinki, Finland \\ ${ }^{\mathrm{d}}$ Department of Psychiatry, University of Helsinki, Finland
}

\section{A R T I C L E I N F O}

\section{Keywords:}

Indoor air

Health-related quality of life (HRQoL)

Depression

Anxiety

Health complaints

Disability

Persistent somatic symptoms

\begin{abstract}
A B S T R A C T
Objective: Nonspecific health complaints associated with indoor air are common in work environments. In some individuals, symptoms become persistent without an adequate explanation. The aim was to study factors that associate with the health-related quality of life (HRQoL) of employees with persistent, nonspecific indoor-airrelated symptomatology.

Methods: We present baseline results of a randomized controlled trial of interventions targeted on the HRQoL of the employees with indoor-air-associated nonspecific symptoms. The main participant-inclusion criterion was the presence of persistent indoor-air-related multiorgan symptoms with no known pathophysiological or environment-related explanation. As a comparison for participants' HRQoL $(n=52)$ we used data from the general-population Health 2011 study (BRIF8901) including information on subjects matched to the participants' working status and age and subjects with asthma, anxiety or depressive disorder, or other chronic conditions with work disability.

Results: The participants showed greater and a clinically significant impairment of HRQoL [M $=0.83$, $\mathrm{SE}=0.013]$ than individuals from the general population $[\mathrm{M}=0.95, \mathrm{SE}=0.001, p<.001$, Hedges' $\mathrm{g}=2.33]$ and those with asthma $[\mathrm{M}=0.93, \mathrm{SE}=0.005, \mathrm{p}<.001$, Hedges' $\mathrm{g}=1.46]$, anxiety and depressive disorder $[\mathrm{M}=0.89, \mathrm{SE}=0.006, \mathrm{p}<.001$, Hedges' $\mathrm{g}=0.73]$, or a chronic condition with work disability $[\mathrm{M}=0.91$, $\mathrm{SE}=0.003, \mathrm{p}<.001$, Hedges' $\mathrm{g}=1.11]$. Prevalent symptoms of depression, anxiety, and insomnia and poor recovery from work were associated with a poor HRQoL.

Conclusions: Individuals with nonspecific indoor-air-associated symptoms have a poorer HRQoL than individuals in the general population with a globally burdensome disease. Psychological distress associated with a poor HRQoL should be considered in the making of decisions about the treatment of these patients.

Trial registration: ClinicalTrials.gov, NCT02069002
\end{abstract}

\section{Introduction}

Health complaints associated with indoor air are common in nonindustrial office work environments [1,2]. A study conducted in eight European countries showed that over one-third of office workers report complaints about indoor air quality [2] (see also [3]). For some people indoor-air-related health complaints become persistent and are associated with impaired quality of life and disability [4-6]. Subjects with these complaints may attribute their symptoms to poor indoor air even in an environment that has contaminant levels far below those toxicologically established to cause harmuful effects [7-9]. Indoor-air-related symptomatology may persist among some people despite improvements in air quality [4,10-14]. It has also been shown in clinical settings that the condition is not always adequately explained by medical causes [14], and attributions to other enviromental triggers are reported to overlap with the prolonged condition [15]. The most frequent health complaints related to indoor-air include respiratory symptoms such as coughing, breathlessness, or a sore throat, as well as

\footnotetext{
* Corresponding authors at: Topeliuksenkatu 41 b, 00250 Helsinki, Finland.

E-mail addresses: sanna.selinheimo@ttl.fi (S. Selinheimo), aki.vuokko@ttl.fi (A. Vuokko), christel.hublin@ttl.fi (C. Hublin), heli.jarnefelt@ttl.fi (H. Järnefelt), kirsi.karvala@ttl.fi (K. Karvala), markku.sainio@ttl.fi (M. Sainio), hille.suojalehto@ttl.fi (H. Suojalehto), jaana.suvisaari@thl.fi (J. Suvisaari), tiina.paunio@thl.fi (T. Paunio).
} 
nonspecific complaints including lightheadedness, fatigue, dizziness, and memory and gastrointestinal problems without an identifiable medical explanation [16]. The burden of these symptoms challenges the healthcare system. For example, one fifth of working-age women and one tenth of working-age men in Finland report symptoms associated with workplace indoor air, and frequent healthcare visits are related to those symptoms. In comparison, of these same working-age women and men, only 6 and $4 \%$ report symptoms associated with indoor air at home. [17]

Health-related quality of life (HRQoL) has become an important outcome measure among people with persistent health complaints. It takes into account people's subjective evaluation of their health and it supports the surveillance of healthcare actions $[18,19]$. Subjective and persistent nonspecific health complaints are a challenge in healthcare operations if they are not covered by standard care guidelines. This may result in patients having unpleasant repeat experiences of seeking help from healthcare providers $[20,21]$ and facing degrees of uncertainty and disappointment if the burden of their condition cannot be operationalized or treated in a standard manner [22].

Some specific stable personality traits and state characteristics have been linked to HRQoL patterns and health outcomes. The personality pattern of neuroticism, a pervasive tendency to experience negative feelings such as anxiety or difficulties coping with stressors, has been consistently linked to a reduced quality of life and to a perceived poorer health status among individuals suffering from well-defined somatic diseases such as asthma [23-25]. Neuroticism is also suggested to associate with increased indoor-air-related symptom reports [26], indicating that it facilitates the attribution of health complaints to environmental factors [27]. Further, it has been shown in populationbased studies that both mental-health problems and chronic somatic diseases are associated with diminished HRQoL [19,28]. A number of studies report comorbidity of these conditions in cases of indoor-airassociated health complaints $[3,14,16]$. One might therefore assume that psychiatric symptoms are also associated with poor HRQoL in cases of persistent indoor-air-related symptomatology. Moreover, a resourceoriented approach to peoples' health-promoting abilities has also been linked to HRQoL research. An ability called sense of coherence (SOC) has been constantly shown to protect health independently of stressful situations [25], including among individuals with indoor-air-related health problems [29]. However, despite the wide array of research on factors associated with health outcomes among people with indoor-airrelated complaints, the burden of these factors remains unknown in comparison with that of chronic diseases in the general population.

There is ongoing debate about the theoretical explanations of indoor-air-related conditions [16,30,31], and the variety of hypotheses is reflected in clinical practice as well [32-35]. Irrespective of the etiology, the recognition of individual factors that affect HRQoL could help in the targeting of healthcare operations in cases in which there is a considerable threat of disability related to persistent indoor-air-related health complaints.

The aim of this study is to give a descriptive analysis of HRQoL data on a group of participants in a well-defined working population, who report indoor-air-associated nonspecific health complaints. To provide a frame of reference, we compare participants' HRQoL to data from a larger representative sample of the general population who are comparable in terms of working status and age. Further, those in the general population with asthma, anxiety or depressive disorder, or some other chronic condition with work disability, were identified and compared separately with the study participants. Another aim was to find out whether those in the group with nonspecific indoor-air-related health complaints experienced psychological distress and, if so, whether it was associated with their HRQoL.

\section{Materials and methods}

\subsection{Study design}

The population for this study includes participants recruited for a randomized clinical trial carried out in Finland by researchers at the Finnish Institute of Occupational Health (FIOH) between the years 2014 and 2018 [36]. Volunteer participants were recruited from occupational-health-service units during 2014-2017. A physician specialized in occupational health evaluated the participants in line with the inclusion criteria. The main criteria were: (i) recurrent and persistent multiorgan symptoms including respiratory symptoms and disability that the participants attributed to indoor air in the workplace; (ii) symptoms had no known medical or environment-exposure-related explanation; and (iii) the symptoms occurred in more than one indoor environment or despite workplace adjustments (including repairs). The cases were identified based on idiopathic environmental intolerance criteria compatible with those proposed by Lacour et al. in 2005 [9]. A two-week diurnal peak-expiratory-flow (PEF) measurement and a bronchial hyperresponsiveness test $[37,38]$ were taken to exclude undiagnosed or uncontrolled asthma as a cause of respiratory symptoms. Those with self-reported physician-diagnosed asthma also filled out the Asthma Control Test (ACT) [39] questionnaire to evaluate its control. A detailed description of the sampling and data-collection procedure is given in an earlier article on the study protocol (see [36]).

The15D questionnaire [40] was used to assess the primary outcome, HRQoL. The participants' HRQoL scores were compared with available population-based 15D reference values based on the Health 2011 Survey. The Health 2011 was a follow-up study of the comprehensive Health 2000 Survey [41,42] that was administered to a representative sample of the Finnish population. The reference values used here included information on subjects with valid 15D scores $(n=1792)$ who were comparable with our study participants in terms of working status and age (29 to 56 years). Of the subjects, 148 reported asthma diagnosed by a physician, and 167 had a depressive or anxiety disorder diagnosed by a structured interview (the Munich version of the Composite International Diagnostic Interview) [43]. In addition, 455 subjects reported a chronic condition or disability or some other condition that had lasted more than three months and affected their work ability and daily functioning. Although two participants in our study were under the age of 29 , the population-based data were available only for subjects aged 29 years and older.

\subsection{Subjects}

The initial pool of recruits for the randomized clinical trial included 75 individuals, of whom 15 did not meet all the inclusion criteria when assessed at the $\mathrm{FIOH}$, for the following reasons: asthma in poor control or other medical reason $(n=5)$, pregnancy $(n=1)$, symptoms improved $(n=2)$, change in work status $(n=2)$, no work disability $(n=1)$, other reasons $(n=4)$. All of the 60 recruits meeting the inclusion criteria were given clinical health examinations, following which eight dropped out $(n=6$, unmotivated or could not engage in the study; $n=1$, could not be reached; and $n=1$, did not fulfill the inclusion criteria). The final sample used in the analysis comprised 52 participants $(92 \%$ women, average age 44.8 years $[S D=8.9]$ ) who completed the recruitment questionnaire, the clinical examination, and the study questionnaire (baseline) before the clinical trial interventions. Table 1 presents the demographic characteristics of both the study sample and the reference sample.

The mean onset of recurrent indoor-air-associated symptoms was 45 months before the recruitment (median $=30$ months, range from two to 286 months). The most common self-reported physician-diagnosed comorbidities were allergic rhinitis $(n=22,42.3 \%)$, asthma $(n=15,28.8 \%)$, migraine $(\mathrm{n}=15,28.8 \%)$, atopic dermatitis $(\mathrm{n}=15$, $28.8 \%)$, depression $(n=15,28.8 \%)$ and high blood pressure $(n=13$, 
Table 1

Demographic data on the study participants $(n=52)$ and the health 2011 survey subsample reference group $(n=1792)$.

\begin{tabular}{|c|c|c|c|c|c|c|}
\hline & & \multicolumn{2}{|c|}{$\begin{array}{l}\text { Study sample } \\
(\mathrm{n}=52)\end{array}$} & \multicolumn{2}{|c|}{$\begin{array}{l}\text { Health } 2011 \\
(\mathrm{n}=1792)\end{array}$} & \multirow[b]{2}{*}{$\chi^{2}$ test, $p$} \\
\hline & & $\mathrm{N}$ & $(\mathrm{N} \%)$ & $\mathrm{N}$ & (N \%) & \\
\hline \multirow[t]{2}{*}{ Gender } & Female & 48 & (92.3) & 993 & $(55,4)$ & $<0.001$ \\
\hline & Male & 4 & $(7.7)$ & 799 & $(44.6)$ & \\
\hline \multirow[t]{5}{*}{ Marital status } & Unmarried & 13 & $(25.0)$ & 193 & $(10.8)$ & $=0.005$ \\
\hline & Married & 21 & $(40.4)$ & 1115 & $(62.2)$ & \\
\hline & Cohabiting & 13 & $(25.0)$ & 327 & $(18.2)$ & \\
\hline & Divorced & 5 & $(9.6)$ & 144 & $(8.0)$ & \\
\hline & Widowed & & & 13 & $(0.7)$ & \\
\hline \multirow[t]{4}{*}{ Educational level } & Graduate & 1 & (1.9) & 124 & $(6.9)$ & $<0.001$ \\
\hline & $\begin{array}{l}\text { Lower } \\
\text { secondary }\end{array}$ & 12 & $(23.1)$ & 660 & $(36.8)$ & \\
\hline & $\begin{array}{l}\text { Higher } \\
\text { secondary }\end{array}$ & 38 & $(73.1)$ & 1008 & $(56.3)$ & \\
\hline & Unknown & 1 & (1.9) & 0 & 0 & \\
\hline \multirow[t]{3}{*}{ Smoking } & Never & 40 & (76.9) & 932 & $(52.4)$ & $=0.002$ \\
\hline & Ex-smoker & 8 & (15.4) & 422 & $(23.7)$ & \\
\hline & Yes & 4 & $(7.7)$ & 425 & $(23.9)$ & \\
\hline \multirow{2}{*}{\multicolumn{2}{|c|}{$\begin{array}{l}\text { High alcohol } \\
\text { consumption }^{\mathrm{a}}\end{array}$}} & 7 & (13) & 553 & $(30.9)$ & $=0.02$ \\
\hline & & Mean & SD & Mean & SD & \\
\hline \multicolumn{2}{|l|}{ Age } & 44.8 & 8.9 & 44.8 & 7.5 & \\
\hline \multicolumn{2}{|l|}{ Body Mass Index } & 26.4 & 5.0 & 26.4 & 4.6 & \\
\hline
\end{tabular}

a The AUDIT alcohol consumption questionnaire (AUDIT-C) = Sum score of the first three items of the alcohol use disorders identification test, cut-off score $>4$ refers to hazardous alcohol use in women and $>5$ refers to hazardous alcohol use in men [44].

25.0\%). No medical comorbidity was found in 10 participants (19.2\%). The current pharmacological treatments were analgesics (42.3\%), antihistamines (30.7\%), asthma medication $(28.8 \%)$ and cardiovascular medicines $(26.9 \%)$. Two participants reported taking no medication during the four weeks before the study. Table 2 presents the clinical and work-related characteristics of the sample.

Among the 15 participants with asthma, the ACT scores indicated that the condition was "controlled" in nine participants (ACT $\geq 20$ points), "not well-controlled" in five participants (ACT 16-19 points), and "uncontrolled" in one participant (ACT $\leq 15$ points). Spirometry detected abnormal lung function in three cases. One patient had bronchial hyperresponsiveness (moderate), and one participant had abnormal PEF monitoring. On the basis of the respiratory-functioning measurements a pulmonologist evaluated the participants with asthma as not having uncontrolled asthma, and that poor asthma control did not fully explain their symptoms.

\subsection{Outcome variables}

The primary outcome measure here is HRQoL as assessed on the 15D $[40,45]$. The $15 \mathrm{D}$ is a utility-based generic, standardized measure, comprising the following 15 dimensions that describe physical, mental, and social well-being: mobility, vision, hearing, breathing, sleeping, eating, speech, excretion, usual activities, mental function, discomfort and symptoms, depression, distress, vitality, and sexual activity. Each dimension is graded by the respondent on a scale ranging between 1 and 5 , where 1 indicates an experience of no problems at all with the dimension and 5 indicates severe problems. The 15D can be used to measure a vast number of health states. We used the 15D data both to derive $15 \mathrm{D}$ overall scores with values from 1 (full health) to 0 (being dead), and to obtain dimensional symptom profiles that are comparable with the Health 2011 subsample-based reference values.

Secondary measures of personality traits, SOC, and psychiatric symptoms and other temporary states were assessed on structured selfreport questionnaires. Personality traits were assessed on the Extra Short Five questionnaire, which measures facets of the five-factor model: neuroticism, extraversion, openness to experience,

Table 2

The clinical and work characteristics of the study participants $(n=52)$.

\begin{tabular}{|c|c|c|c|c|c|c|c|}
\hline & & $\mathrm{N}$ & $(\mathrm{N} \%)$ & M & (SD) & $\mathrm{Me}$ & Min - Max \\
\hline Symptom duration in months ${ }^{a}$ & & & & 44.9 & $(50.4)$ & 30.0 & {$[2,286]$} \\
\hline Years in working life & & & & 20.3 & $(9.6)$ & 20.0 & {$[2,39]$} \\
\hline Years in current work & & & & 8.0 & $(8.9)$ & 5.0 & {$[0,38]$} \\
\hline Self-reported sick leave in days ${ }^{b}$ & & & & 21.3 & $(34.0)$ & 7.5 & {$[0,166]$} \\
\hline Self-reported physician visits ${ }^{\mathrm{c}}$ & & & & 6.0 & $(5.6)$ & 5.0 & {$[0,30]$} \\
\hline Self-reported physician visits - indoor air ${ }^{d}$ & & & & 5.2 & $(5.2)$ & 4.0 & {$[0,30]$} \\
\hline Work ability & & & & 6.7 & $(1.7)$ & 7.0 & {$[1,9]$} \\
\hline \multirow[t]{3}{*}{ Spirometry } & FVC\% predicted & & & 97.1 & $(10.3)$ & & \\
\hline & FEV1\% predicted & & & 94.5 & $(10.3)$ & & \\
\hline & FEV1/FVC & & & 80.1 & $(5.1)$ & & \\
\hline \multirow[t]{4}{*}{ Bronchial hyperresponsiveness ${ }^{e}$} & Severe & 0 & & & & & \\
\hline & Moderate & 1 & $(2.0)$ & & & & \\
\hline & Mild & 5 & $(10.2)$ & & & & \\
\hline & None & 43 & $(87.8)$ & & & & \\
\hline Daily diurnal PEF variability over two weeks & Significant bronchial reversibility $\geq 3$ & 1 & & & & & \\
\hline \multirow[t]{3}{*}{ Own prognosis of work ability in 2 years' time } & Unlikely & 1 & $(1.9)$ & & & & \\
\hline & Not certain & 18 & $(34.6)$ & & & & \\
\hline & Relatively certain & 33 & $(63.5)$ & & & & \\
\hline \multirow[t]{4}{*}{ Self-reported comorbid disease ${ }^{g}$} & None & 10 & $(19.2)$ & & & & \\
\hline & Physical ${ }^{\mathrm{f}}$ & 20 & $(38.5)$ & & & & \\
\hline & Mental & 2 & $(3.8)$ & & & & \\
\hline & Physical and mental & 20 & $(38.5)$ & & & & \\
\hline
\end{tabular}

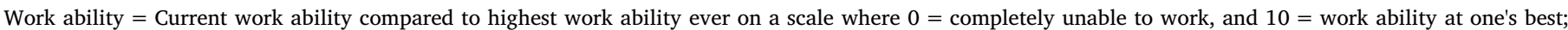
FEV1, forced expiratory volume in one second; FVC, forced vital capacity; IgE, immunoglobulin E; PEF, peak expiratory flow.

a Months

b Days during past six months

c Times during past six months

d Times during past six months because of indoor-air-associated symptoms

e $n=49$, examination was not done $(n=1$, medication in use prevented the examination; $n=1$ side effects related to medical examination; $\mathrm{n}=1$ examination was replaced with spirometry with bronchodilator, result was normal);

${ }^{\mathrm{f}}$ Two of the participants also reported job-related burn-out, which is not diagnosed as a mental disease in the Finnish healthcare system, however. 
Table 3

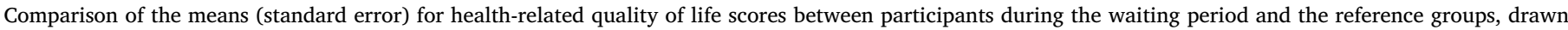
from the health 2011 survey.

Health-related quality of life

\begin{tabular}{|c|c|c|c|c|c|c|c|c|}
\hline \multicolumn{2}{|l|}{ Study sample } & \multicolumn{3}{|c|}{ Health 2011: Reference groups } & \multirow[b]{2}{*}{ Ancova $(F)$} & \multirow[b]{2}{*}{$d f$} & \multirow[b]{2}{*}{$p$} & \multirow[b]{2}{*}{ Adjusted $R^{2}$} \\
\hline Observed mean & Adjusted mean & & Observed mean & Adjusted mean & & & & \\
\hline \multirow[t]{4}{*}{$0.83(0.013)$} & $0.85(0.015)$ & All & $0.95(0.001)$ & $0.96(0.014)$ & 204.5 & (1. 1809) & $<0.001$ & 0.15 \\
\hline & $0.86(0.025)$ & Asthma & $0.93(0.005)$ & $0.95(0.024)$ & 59.40 & $(1,183)$ & $<0.001$ & 0.27 \\
\hline & $0.86(0.027)$ & Depression or anxiety & $0.89(0.006)$ & $0.92(0.025)$ & 14.61 & $(1,199)$ & $<0.001$ & 0.07 \\
\hline & $0.84(0.018)$ & Chronic condition & $0.91(0.003)$ & $0.93(0.018)$ & 58.76 & $(1,491)$ & $<0.001$ & 0.16 \\
\hline
\end{tabular}

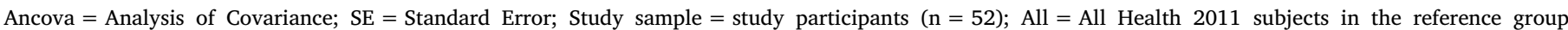

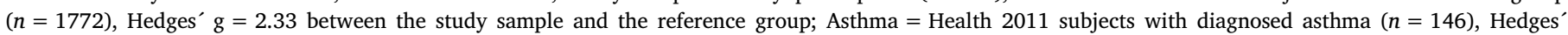

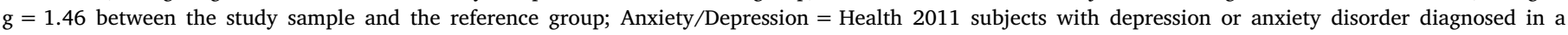

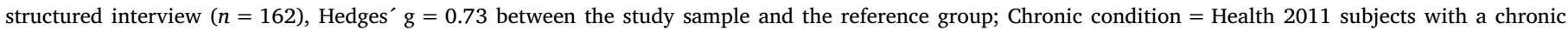

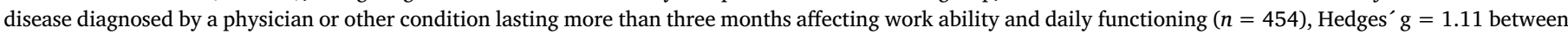

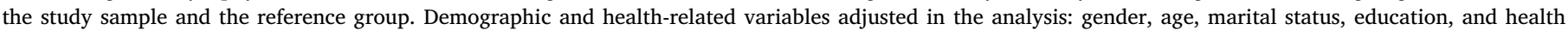
related variables (smoking, alcohol consumption, and body mass index).

agreeableness, and conscientiousness [46]. The Extra Short Five has proved to be a reliable and valid instrument $[46,47]$. SOC was assessed on the Finnish SOC-13 scale $[48,49]$. The psychometric properties of SOC-13 have proven to be good, and the instrument has been validated both in general populations and in several clinical populations [25,50].

The Patient Health Questionnaire-9 [51] and General Anxiety Disorder-7 [52] were used to assess symptoms of depressive and anxiety disorder. In addition, we used the Insomnia Severity Index to assess the severity of insomnia [53]. Psychiatric and somatic symptoms were also assessed on the Global Severity Index of Symptom Checklist 90 [54]. Work-related fatigue was measured on the Need for Recovery scale, which assesses the frequency of problems in recovering from work [55]. The psychometric properties of these measurements have been shown to be good [56-60]. We used two scales from the Quick Environmental Exposure and Sensitivity Inventory (QEESI), Chemical Intolerance and Life Impact, to assess multiple chemical intolerance [61]. We also used the Penny State Worry Questionnaire [62], which concerns the tendency, intensity, and uncontrollability of general worry, to measure worrying as an independent construct of anxiety. Psychological inflexibility was assessed on the Acceptance and Action Questionnaire-II $[63,64]$. The Cronbach's $\alpha$ for each of these outcome questionnaire scales varied from 0.83 to 0.97 .

HRQoL, personality traits, and SOC were assessed during the waiting period before the clinical examination at the FIOH. Other measurements were taken after the clinical examinations, at the same time as the HRQoL re-evaluation (timepoint baseline).

\subsection{Statistical methods}

Tables 1 and 2 contain summaries of the demographic data. The differences in the distributions of the patients' clinical characteristics were evaluated using $\chi 2$ tests. Data were checked for outliers on a scatter plot of the primary-outcome overall score, and one outlier was detected. However, because the participant fullfilled the inclusion criteria there was no reason to exclude the data, hence the analyses were repeated both including and excluding the outlier. The results were similar in both cases and thus are reported for the analyses that include all the participants. The HRQoL scores of the participants were compared with those of the reference groups by analysis of covariance. Effect sizes were computed as Hedges' g. The demographic and healthrelated variables available in both datasets were adjusted in the models. The distribution of the HRQoL dimensional profiles were compared with Mann Whitney $U$ tests. In addtition, given that women constituted $92 \%$ of the participants, statistical analyses involving HRQoL were conducted both for women only and for both genders. Student's $t$-tests were used to assess the significance of any group differences in the mean HRQoL based on divisions according to the clinical cut-off scores in the psychiatric measurements (no complaints - complaints). Pearson's $r$ was used to measure the correlations between continuous psychological measurements with no diagnosis-based or other well-defined cut-off scores. Analyses comparing five personality patterns and SOC were Bonferroni corrected. The level of significance was set at $p<.05$, and results based on an effect size above small $\left(r^{2}>0.2\right)$ are presented. To identify the determinants of HRQoL we used multiple linear regression (enter method) to analyze the associations between the psychiatric and psychological measurements. So as to avoid multicollinearity we considered tolerances above 0.5 and variance inflator factors under 2 acceptable, and chose the model with the significantly best adjusted R-square. We used version 25.0 of IBM-SPSS for Windows (SPSS Illinois, Chicago, Illinois, USA) for the statistical analyses.

\section{Results}

\subsection{Comparison of the HRQoL scores among the study participants and the reference groups}

The participants' 15D-derived HRQoL scores were significantly different from those of the reference-group subjects, and from those of subjects with asthma, depression or anxiety disorder, or with a chronic condition affecting their work ability and daily functioning. Table 3 presents the results of the analyses of covariance. Fig. 1 shows the mean results for the 15D, item by item, for the study participants and the reference groups. The results for all participants and for female participants only were robust when compared with the different reference groups (Appendix 1). The results shown here cover all participants.

\subsection{HRQoL associated with psychiatric symptoms}

High levels of insomnia and high levels of depressive- or anxietydisorder-related symptoms among the study participants were associated with a decreased HRQoL. A high level of chemical intolerance was not statistically significantly related to HRQoL (Table 4).

Problems in recovery from work, a high impact of chemical intolerance on everyday life, and symptoms of depressive disorder were significantly associated with a poor HRQoL. A significant model emerged $\left(\mathrm{R}^{2}=0.72, \mathrm{~F}(3,48)=45.62, p<.001\right)$ (Model 1 , Table 5). Having problems recovering from work was no longer significantly associated with a poor HRQoL $(p=.06)$ when the analyses were adjusted $\left(\mathrm{R}^{2}=0.71,(\mathrm{~F}(3,44)=38.48, \mathrm{p}<.001)\right.$ (Model 2, Table 5). Other variables presented in Fig. 2 were not significantly associated with HRQoL when added to the model. Fig. 2 presents the correlations between the psychological factors and HRQoL measured after the 


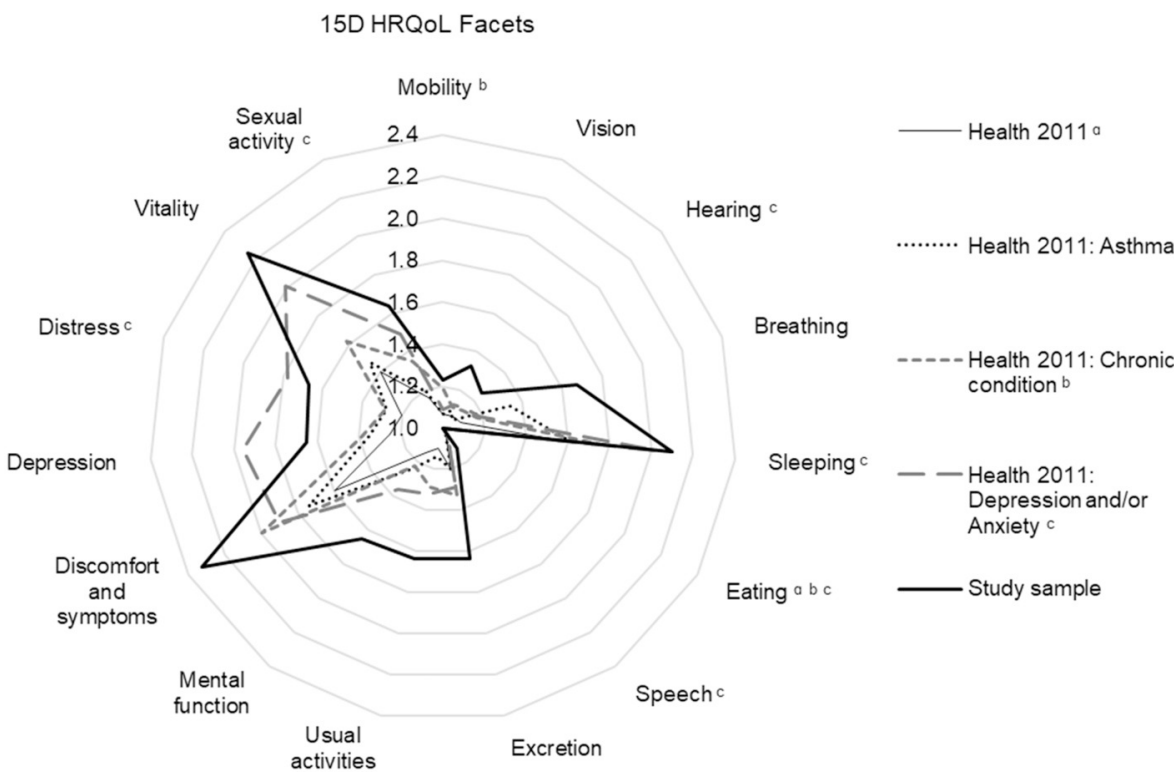

Fig. 1. Dimensions of the 15D-based health-related quality of life for the study participants and the reference groups $(1=$ perfect functioning on the dimension, $5=$ severe disability on the dimension). Health 2011: all subjects in the reference data $(n=1792)$; Health 2011: Asthma $=$ Health 2011 subjects with diagnosed asthma $(n=148)$; Health 2011: Anxiety or depression $=$ Health 2011 subjects with depression or anxiety disorder diagnosed in a structured interview $(n=167)$; Health 2011: Chronic condition $=$ Health 2011 subjects with a chronic disease diagnosed by a physician or other condition lasting more than three months affecting work ability and daily functioning. The study sample $(n=52)=$ participants in the RCT study. ${ }^{\text {a }}$ The distribution of the 15D-dimension in all subjects in Health 2011 and Health 2011: subjects with asthma and the Study samples is the same (Mann Whitney $\mathrm{U}){ }^{\mathrm{b}}$ The distribution of the $15 \mathrm{D}$-dimension in Health 2011: chronic condition and the Study samples is the same (Mann Whitney U). ${ }^{\mathrm{c}}$ The distribution of the 15D-dimension in Health 2011: anxiety and depression and the Study samples is the same (Mann Whitney U).

health examinations.

Finally, we tested whether the prevalence of comorbid diseases (none or physical and/or mental) was associated with the clinical characteristics. The chi-square test results showed no significant association between participants with and without comorbid disease and the time from the first symptom onset $\left(\chi^{2}(40)=36.90, p=.61\right)$, the number of sick-leave days during the previous six months $\left(\chi^{2}(28)=29.97, p=.37\right)$, the number of self-reported physician visits $(\chi 2(14)=8.68, p=.85)$ or visits because of the indoor-air-related condition $(\chi 2(13)=13.16, p=.44)$. Further, there was no significant relationship between the time from the first symptom onset (in months) and HRQoL $(r=0.001, n=52, p=.99$ ), and no significant associations were found between comorbid diseases and HRQoL [F $(1,38)=0.03, p=.88]$ following adjustment for demographic and health-related factors.

\subsection{HRQoL associated with individual traits}

Good HRQoL and high SOC had a positive, significant correlation ( $r=0.49, p=.005$, two-tailed), explaining $23.6 \%$ of the variation. Following Bonferroni correction between all traits, neuroticism had a significantly negative correlation with HRQoL $(r=-0.45, n=52$, $p=.005$, two-tailed) explaining $20.2 \%$ of the variation. HRQoL also correlated with other personality factors (conscientiousness $r=0.31$, extraversion $r=0.26$, openness to experiences $r=-0.10$ and agreeableness $r=0.26$ ). However, the effect sizes remained modest and after

Bonferroni correction, none of them were statistically significant.

\section{Discussion}

Our results indicate that workers with persistent indoor-air-related nonspecific symptomatology generally have lower HRQoL compared to general-population reference groups with globally burdensome diseases. We also found a wider range of subjective health complaints, measured on dimensions of the $15 \mathrm{D}$, compared to reference groups derived from the general population with either a diagnosis of asthma, anxiety or depressive disorder, or with a self-reported chronic disease or other condition affecting work ability and daily functioning. Higher levels of trait neuroticism and some types of psychological distress (symptoms of depression, anxiety, insufficient recovery in terms of symptoms of insomnia, and poor recovery from work) were associated with a low HRQoL. However, HRQoL was not associated with the time from symptom onset or with comorbid diseases.

Studies conducted among representative samples of Finnish people imply that HRQoL remained stable in the working-age population between 2000 and 2017 [17,41]. Both age and the presence of chronic somatic and psychiatric conditions have been shown to decrease HRQoL [65], and psychiatric disorders have been shown to have a more detrimental effect than other medical conditions among the under-60s [65]. In our study, $42 \%$ of the participants reported a psychiatric disorder (depression and/or anxiety) previously diagnosed by a physician, whereas 21 and 15\%, respectively, reported current symptoms of

Table 4

Means and standard deviations of the health-related quality of life (HRQoL) scores by symptom screening cut-offs after the clinical examinations.

\begin{tabular}{|c|c|c|c|c|c|c|c|}
\hline \multirow[b]{2}{*}{ PHQ } & \multicolumn{4}{|c|}{ HRQoL according to cut-off score M (SD) } & \multirow{2}{*}{$\begin{array}{l}t \\
5.11\end{array}$} & \multirow{2}{*}{$\frac{d f}{50}$} & \multirow{2}{*}{$\frac{p}{<0.001}$} \\
\hline & $n=11$ & $0.76(0.09)$ & $n=41$ & $0.88(0.06)$ & & & \\
\hline GAD & $n=8$ & $0.73(0.09)$ & $n=44$ & $0.87(0.07)$ & 4.99 & 50 & $<0.001$ \\
\hline \multicolumn{8}{|l|}{ QEESI } \\
\hline Chemical intolerance & $\mathrm{n}=31$ & $0.84(0.07)$ & $\mathrm{n}=21$ & $0.87(0.10)$ & 1.01 & 50 & 0.32 \\
\hline Life Impact & $n=35$ & $0.83(0.09)$ & $\mathrm{n}=17$ & $0.89(0.07)$ & 2.37 & 50 & 0.02 \\
\hline
\end{tabular}

$\mathrm{M}=$ Mean; $\mathrm{SD}=$ Standard Deviation; $\mathrm{PHQ}=$ Patient Health Questionnaire (Study sample $\mathrm{M}=3.33, \mathrm{SD}=3.71$ ). Cut-off score $>4$ refers to mild to severe depression; ISI = Insomnia Severity Index $(\mathrm{M}=6.31$, SD 5.20). Cut-off score $>7$ refers to insomnia; $\mathrm{GAD}=$ Generalized Anxiety Disorder (Study sample $\mathrm{M}=2.04$, $\mathrm{SD}=2.75$ ); cut-off score $>4$ refers to mild to severe anxiety; QEESI = Quick Environmental Exposure and Sensitivity Inventory, Chemical Intolerance (Study sample $\mathrm{M}=48.42, \mathrm{SD}=24.55$ ); cut-off score $>40$ refers to a high probability of chemical intolerance and Life Impact (Study sample $\mathrm{M}=39.13$, $\mathrm{SD}=25.58) ;>24$ refers to a high impact of intolerance on everyday life. $N=52$. 
Table 5

Predictors of health-related quality of life as shown in the linear regression.

\begin{tabular}{|c|c|c|c|c|c|c|c|c|c|c|}
\hline & \multicolumn{5}{|l|}{ Model 1} & \multicolumn{5}{|l|}{ Model 2} \\
\hline & $B$ & $95 \%$ CI for $B$ & $S E B$ & $\beta$ & $p$ & $B$ & $95 \%$ CI for B & $S E B$ & $\beta$ & $p$ \\
\hline NRF & -0.003 & $(-0.005,0.000)$ & 0.001 & -0.197 & 0.045 & -0.003 & $(-0.005,0.000)$ & 0.001 & -0.203 & 0.06 \\
\hline Qeesi LI & -0.001 & $(-0.002,-0.001)$ & 0.000 & -0.332 & $<0.001$ & -0.001 & $(-0.002,-0.001)$ & 0.000 & -0.369 & $<0.001$ \\
\hline PHQ - 9 & -0.013 & $(0.018,-0.009)$ & 0.002 & -0.579 & $<0.001$ & -0.013 & $(-0.018,-0.008)$ & 0.002 & -0.577 & $<0.001$ \\
\hline
\end{tabular}

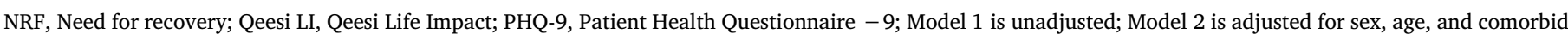
diseases (dummy coded none vs one or more comorbid diseases) and symptom duration in months.

depression or anxiety above clinical cut-off scores. It has been suggested that these factors increase vulnerability to low HRQoL and they are associated with persistent indoor-air-related health complaints [3,31]. Furthermore, there is evidence that they constitute a risk in terms of adverse physical reactions related to environmental factors [66]. However, although symptoms of depression and anxiety were associated with poor HRQoL, we did not assess their onset in our study. Therefore, we cannot evaluate the extent to which depression and anxiety are a consequence of adjusting to persistent symptomatology related to indoor air, a sign of other processes, a cause of or underlying reason for the prolonging of somatic symptoms, or all of these. However, Van Boven et al. [67] showed that unexplained physical symptoms are strongly associated with a depression episode in primary-care settings. Their results support our findings indicating that signs of depression are associated with somatic symptoms without an adequate explanation, and we assume that these states affect each other and worsen HRQoL. Thus, patients with persistent indoor-air-related symptoms seeking primary care should be screened for symptoms of psychological distress.

Our results are consistent with the findings reported in previous studies on severe disability among patients with indoor-air-associated symptoms. Several studies have shown comorbidity of somatic and psychiatric disorders with other environment-related symptomatology or intolerance $[68,69]$. However, we studied the associations of longterm stable dispositions and psychological distress with HRQoL among workers with no severe work disability in line with Runeson et al. [70]. They suggested that the association between neuroticism and poor HRQoL may not merely reflect secondary reactions to indoor-air-associated nonspecific health complaints [70]. Our results raise the question of whether a long-term stable disposition can predispose individuals to non-adaptive functioning in prolonged stressful situations or, in the case of SOC, protect them from suspected environmental stress [29]. It is noteworthy that although depression and anxiety have been linked independently with poor HRQoL [71], the participants of our study reported inferior HRQoL compared to groups with globally burdensome diseases or other chronic conditions with disability. Thus, together with current psychological distress, trait-like factors might not just worsen HRQoL but could also make the people vulnerable to indoor air-related health complaints.

Thus far the evidence on treatment options for prolonged indoor-
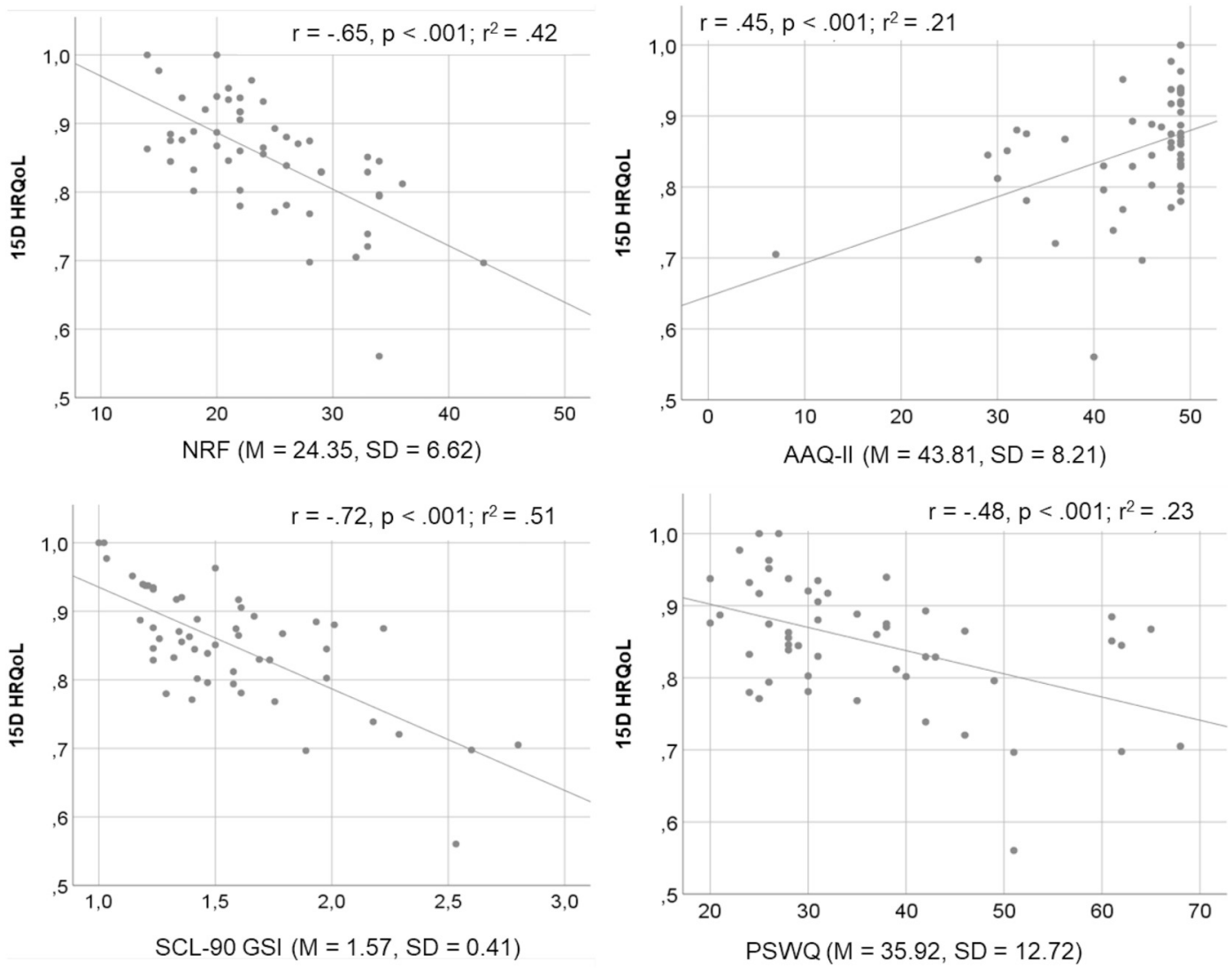

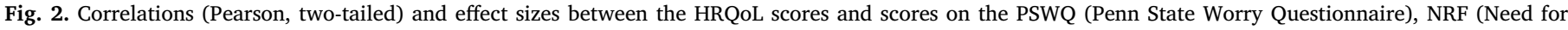
Recovery), AAQ-II (Acceptance and Action Questionnaire - II), and SCL-90 GSI (Symptom Check List -90, Global Severity Index); N = 52. 
air-associated nonspecific symptoms is limited. Cognitive-behavioral psychotherapy (CBT) has shown preliminarily promising results for similar conditions involving nonspecific and persistent health complaints $[72,73]$. It has also been shown that problems of recovery from work as well as depression and insomnia are associated with and even predict higher numbers of somatic health complaints $[57,74,75]$. Thus, it could be assumed from the results of this study that several comorbid states might affect case prognosis. Recent studies have found promising evidence that supporting healthy sleeping patterns through CBT also affects recovery from psychiatric disorders such as depression [76-78]. It has further been suggested that having modern health concerns such as worrying about mold in indoor air is a predictor of somatic symptoms, and that the physical components of HRQoL and symptoms of depression mediate this association [66]. These notions support the tailoring of treatment for psychological distress to individual abilities to enhance health and thereby prevent health complaints from becoming persistent.

The cross-sectional design of our study allows only for speculation as to whether the results reflect a causal relationship between psychological patterns, poor HRQoL, and persistent nonspecific indoor-airrelated symptoms. Despite the methodological challenge, however, it has to be acknowledged that psychosocial components are inherent in all health complaints and diseases in the context of employee discomfort and health complaints in a work environment [26,30,79]. Psychosocial processes may directly constitute stressors, causing symptoms through psychophysiological mechanisms, or they may lead to vicious circles potentiating health complaints. Furthermore, our analyses were based on the reports of occupational physicians on the participants' work environment and health, as well as on participants' self-reported data on health and the work-place environment: the psychosocial climate was not included in the analysis, although there is now some evidence that it plays a role in experiencing and reporting indoor-air-related symptoms $[80,81]$. Thus, together with adopting a more traditional focus on cause-effect relations in this context, research should focus on people's abilities to respond to and seek help for health complaints in which both individual and workplace characteristics play a role. Also on the population level, individual dispositions have been shown to associate with increasingly frequent healthcare visits among subjects with nonspecific and recurrent respiratory health complaints [82]. Targeting these factors in healthcare in parallel with standard medical care would enhance good practice in terms of supporting health-related quality of life [83].

\section{Conclusion}

Our findings indicate that persistent indoor-air-associated nonspecific symptoms are more closely associated with a decreased HRQoL than asthma, depression or anxiety disorder, or even chronic conditions with work disability. Further, both stable traits and symptoms of depressive disorder or other signs of emotional distress affected the HRQoL of employees with persistent indoor-air-associated nonspecific symptoms. Given that self-rated health is a well-known predictor of morbidity $[84,85]$, healthcare actions should focus more on the patient's ability to cope with somatic conditions.

\section{Trial status}

This study has been registered at the ClinicalTrials.gov registry (NCT02069002). Patient enrolment ended in January 2017, and the 12month follow-up results are expected in 2019.

\section{Ethics}

The Coordinating Ethics Committee of the Hospital District of Helsinki and Uusimaa, Finland, has granted approval for this study (number 107/13/03/00/13).

\section{Acknowledgments}

The original data collection was funded by the Finnish Work Environment Fund (ref 113076) and the Social Insurance Institution of Finland (ref 23/26/2014) (to TP). SS was funded by The Research Foundation for Pulmonary Diseases and the Signe and Ane Gyllenberg Foundation.

\section{Contributors}

SS performed the statistical analyses and wrote the first draft the manuscript. All the authors provided feedback on the drafts, and they read and approved the final manuscript.

\section{Competing interests}

All the authors have completed the ICMJE uniform disclosure form at www.icmje.org/coi_disclosure.pdf and declare: Financial support for the submitted work from The Finnish Work Environment Fund (ref 113,076) and the Social Insurance Institution of Finland (KELA) (ref 23/26/2014); KK works as a part-time medical consultant at Varma Mutual Pension Insurance Company; AV works as a part-time medical consultant at OP Insurance Ltd., and has worked as a part-time medical consultant at The Social Insurance Institute of Finland (KELA, until 31.11.2018) and OP Insurance Ltd.; AV was a substitute member of the medical expert group, Unemployment Security Appeal Board (TTLK) (in accordance with the unemployment security commission Act) until 31.12.2017; MS works as a part-time medical advisor to The Finnish Patient Insurance Centre (in accordance with the Patient Injuries Act). These affiliations (AV, KK, MS) caused no conflicts of interest regarding this article. None of these institutions profits financially or non-financially from studying and publishing the methods and results of this intervention study. Neither the authors' institutions nor the funders had any authority over trial activities or the preparing of the manuscript.

\section{Patient consent}

Obtained.

\section{Appendix A. Supplementary data}

Supplementary data to this article can be found online at https:// doi.org/10.1016/j.jpsychores.2019.03.181.

\section{References}

[1] WHO, Indoor air pollutants: exposure and health effects, in: M. Jantunen, J.J.K. Jaakkola, M. Kzyzanowski (Eds.), EURO Reports and Studies 78, WHO Regional Office for Europe, Copenhagen, 1983.

[2] P. Bluyssen, et al, Self-reported health and comfort in 'modern'office buildings: first results from the European OFFICAIR study, Indoor Air 26 (2) (2016) 298-317.

[3] N. Magnavita, Work-related symptoms in indoor environments: a puzzling problem for the occupational physician, Int. Arch. Occup. Environ. Health 88 (2) (2015) 185-196.

[4] B. Edvardsson, et al., Medical and social prognoses of non-specific building-related symptoms (sick building syndrome): a follow-up study of patients previously referred to hospital, Int. Arch. Occup. Environ. Health 81 (7) (2008) 805-812.

[5] K. Karvala, et al., Quality of life of patients with asthma related to damp and moldy work environments, Scand. J. Work Environ. Health (2013) 96-105.

[6] K. Karvala, et al., Asthma related to workplace dampness and impaired work ability, Int. Arch. Occup. Environ. Health 87 (1) (2014) 1-11.

[7] O. Van den Bergh, et al., Idiopathic environmental intolerance: a comprehensive model, Clin. Psychol. Sci. 5 (3) (2017) 551-567.

[8] J. Das-Munshi, G.J. Rubin, S. Wessely, Multiple chemical sensitivities: review, Current Opinion in Otolaryngology \& Head and Neck Surgery 15 (4) (2007) 274-280.

[9] M. Lacour, et al., Multiple chemical sensitivity syndrome (MCS)-suggestions for an extension of the US MCS-case definition, Int. J. Hyg. Environ. Health 208 (3) (2005) $141-151$.

[10] M. Al-Ahmad, et al., Symptoms after mould exposure including Stachybotrys chartarum, and comparison with darkroom disease, Allergy 65 (2) (2010) 245-255. 
[11] U. Haverinen-Shaughnessy, et al., Monitoring success of remediation: seven case studies of moisture and mold damaged buildings, Sci. Total Environ. 399 (1) (2008) 19-27.

[12] Y.Y. Iossifova, et al., Lack of respiratory improvement following remediation of a water-damaged office building, Am. J. Ind. Med. 54 (4) (2011) 269-277.

[13] R. Sauni, et al., Remediating buildings damaged by dampness and mould for preventing or reducing respiratory tract symptoms, infections and asthma, Cochrane Database Syst. Rev. (9) (2011) Cd007897.

[14] A. Vuokko, et al., Decreased work ability associated to indoor air problems - an intervention (RCT) to promote health behavior, Neurotoxicology 49 (2015) 59-67.

[15] E. Palmquist, et al., Overlap in prevalence between various types of environmental intolerance, Int. J. Hyg. Environ. Health 217 (4-5) (2014) 427-434.

[16] D. Norbäck, An update on sick building syndrome, Curr. Opin. Allergy Clin. Immunol. 9 (1) (2009) 55-59.

[17] Koponen, P., et al., Terveys, Toimintakyky ja Hyvinvointi Suomessa: FinTerveys 2017-tutkimus.

[18] S. Saarni, Health-Related Quality of Life and Mental Disorders in Finland, (2008).

[19] S.I. Saarni, et al., The impact of 29 chronic conditions on health-related quality of life: a general population survey in Finland using 15D and EQ-5D, Qual. Life Res. 15 (8) (2006) 1403-1414.

[20] J.I. Escobar, et al., Whether medically unexplained or not, three or more concurrent somatic symptoms predict psychopathology and service use in community populations, J. Psychosom. Res. 69 (1) (2010) 1-8.

[21] F.H. Creed, et al., The epidemiology of multiple somatic symptoms, J. Psychosom. Res. 72 (4) (2012) 311-317.

[22] A.J. Dirkzwager, P.F. Verhaak, Patients with persistent medically unexplained symptoms in general practice: characteristics and quality of care, BMC Fam. Pract. 8 (1) (2007) 33

[23] M.O. Van De Ven, R.C. Engels, Quality of life of adolescents with asthma: the role of personality, coping strategies, and symptom reporting, J. Psychosom. Res. 71 (3) (2011) 166-173.

[24] E. Huovinen, J. Kaprio, M. Koskenvuo, Asthma in relation to personality traits, life satisfaction, and stress: a prospective study among 11000 adults, Allergy 56 (10) (2001) 971-977.

[25] M. Eriksson, B. Lindström, Antonovsky's sense of coherence scale and the relation with health: a systematic review, J. Epidemiol. Community Health 60 (5) (2006) 376-381.

[26] M. Gomzi, et al., Sick building syndrome: psychological, somatic, and environmental determinants, Arch. Environ. Occup. Health 62 (3) (2007) 147-155.

[27] K. Österberg, et al., Personality, mental distress, and subjective health complaints among persons with environmental annoyance, Hum. Exp. Toxicol. 26 (3) (2007) $231-241$.

[28] S.I. Saarni, et al., Impact of psychiatric disorders on health-related quality of life: general population survey, Br. J. Psychiatry 190 (4) (2007) 326-332.

[29] R. Runeson, D. Norbäck, H. Stattin, Symptoms and sense of coherence-a follow-up study of personnel from workplace buildings with indoor air problems, Int. Arch. Occup. Environ. Health 76 (1) (2003) 29-38.

[30] A.F. Marmot, et al., Building health: an epidemiological study of "sick building syndrome" in the Whitehall II study, Occup. Environ. Med. 63 (4) (2006) 283-289.

[31] P.M. Bluyssen, et al., Assessment of wellbeing in an indoor office environment, Build. Environ. 46 (12) (2011) 2632-2640.

[32] C. Hausteiner, et al., Dysfunctional cognitions in idiopathic environmental intolerances (IEI)—an integrative psychiatric perspective, Toxicol. Lett. 171 (1-2) (2007) 1-9.

[33] L. Hetherington, J. Battershill, Review of evidence for a toxicological mechanism of idiopathic environmental intolerance, Hum. Exp. Toxicol. 32 (1) (2013) 3-17.

[34] D.A. Katerndahl, et al., Chemical intolerance in primary care settings: prevalence comorbidity, and outcomes, The Annals Family Med. 10 (4) (2012) 357-365.

[35] WHO, WHO guidelines for indoor air quality: Dampness and mould, Cited 2019 March, 2009. https://www.who.int/airpollution/guidelines/dampness-mould/en/.

[36] S. Selinheimo, et al., Comparing cognitive-behavioural psychotherapy and psychoeducation for non-specific symptoms associated with indoor air: a randomised control trial protocol, BMJ Open 6 (6) (2016) e011003.

[37] L. Malmberg, K. Reinikainen, H. Poppius, A rapid dosimetric method with controlled tidal breathing for histamine challenge. Repeatability and distribution of bronchial reactivity in a clinical material, CHEST J. 104 (1) (1993) 164-170.

[38] P. Quanjer, et al., Peak expiratory flow: conclusions and recommendations of a working Party of the European Respiratory Society, Eur. Respir. J. 10 (24) (1997) 2 s.

[39] R.A. Nathan, et al., Development of the asthma control test: a survey for assessing asthma control, J. Allergy Clin. Immunol. 113 (1) (2004) 59-65.

[40] H. Sintonen, The 15D instrument of health-related quality of life: properties and applications, Ann. Med. 33 (5) (2001) 328-336.

[41] S. Koskinen, A. Lundqvist, N. Ristiluoma, Terveys, toimintakyky ja hyvinvointi Suomessa 2011, Raportti: 2012_068, 2012.

[42] Health and functional capacity in Finland, in: A. Aromaa, S. Koskinen (Eds.), Baseline Results of the Health 2000 Health Examination Survey, Publications of the National Public Health Institute, 2004.

[43] H.-U. Wittchen, et al., Test-retest reliability of the computerized DSM-IV version of the Munich-composite international diagnostic interview (M-CIDI), Soc. Psychiatry Psychiatr. Epidemiol. 33 (11) (1998) 568-578.

[44] L. Kriston, et al., Meta-analysis: are 3 questions enough to detect unhealthy alcohol use? Ann. Intern. Med. 149 (12) (2008) 879-888.

[45] H. Sintonen, The 15-d measure of health related quality of life: Reliability, validity and sensitivity of its health state descriptive system, Working Paper 41, National Centre for Health Program Evaluation, Melbourne, 1994.
[46] K. Konstabel, et al., Measuring single constructs by single items: constructing an even shorter version of the "short five" personality inventory, PLoS One 12 (8) (2017) e0182714.

[47] K. Konstabel, et al., The 'short five'(S5): measuring personality traits using comprehensive single items, Eur. J. Personal. 26 (1) (2012) 13-29.

[48] A. Antonovsky, Unraveling the Mystery of Health: How People Manage Stress and Stay Well, Jossey-Bass, 1987.

[49] E. Bernabe, et al., Structure of the sense of coherence scale in a nationally representative sample: the Finnish health 2000 survey, Qual. Life Res. 18 (5) (2009) 629-636.

[50] M. Eriksson, B. Lindström, Validity of Antonovsky's sense of coherence scale: a systematic review, J. Epidemiol. Community Health 59 (6) (2005) 460-466.

[51] K. Kroenke, R.L. Spitzer, J.B. Williams, The Phq-9, J. Gen. Intern. Med. 16 (9) (2001) 606-613.

[52] R.L. Spitzer, et al., A brief measure for assessing generalized anxiety disorder: the GAD-7, Arch. Intern. Med. 166 (10) (2006) 1092-1097.

[53] C.M. Morin, D.H. Barlow, Insomnia: Psychological Assessment and Management, vol. 104, Guilford Press New York, 1993.

[54] L.R. Derogatis, P.A. Cleary, Confirmation of the dimensional structure of the SCL90: a study in construct validation, J. Clin. Psychol. 33 (4) (1977) 981-989.

[55] J.K. Sluiter, The influence of work characteristics on the need for recovery and experienced health: a study on coach drivers, Ergonomics 42 (4) (1999) 573-583.

[56] C.M. Morin, et al., The insomnia severity index: psychometric indicators to detect insomnia cases and evaluate treatment response, Sleep 34 (5) (2011) 601-608.

[57] J. Sluiter, et al., Need for recovery from work related fatigue and its role in the development and prediction of subjective health complaints, Occup. Environ. Med. 60 (Suppl. 1) (2003) i62-i70.

[58] M. Holi, Assessment of psychiatric symptoms using the SCL-90, Faculty of Medicine, Department of Psychiatry, University of Helsinki, Helsinki, 2003.

[59] E. Kaila, et al., ToMaHoK - Toimiva masennuksen hoitokäytäntö työterveyshuollossa, Finnish Institute of Occupational Health, Painojussit Oy, Kerava, 2012.

[60] H. Järnefelt, C. Hublin, Työikäisten unettomuuden hoito, Finnish Institute of Occupational Health, Tammerprint Oy, Tampere, 2012.

[61] C.S. Miller, T.J. Prihoda, The environmental exposure and sensitivity inventory (EESI): a standardized approach for measuring chemical intolerances for research and clinical applications, Toxicol. Ind. Health 15 (3-4) (1999) 370-385.

[62] T.J. Meyer, et al., Development and validation of the penn state worry questionnaire, Behav. Res. Ther. 28 (6) (1990) 487-495.

[63] F.W. Bond, et al., Preliminary psychometric properties of the acceptance and action questionnaire-II: a revised measure of psychological inflexibility and experiential avoidance, Behav. Ther. 42 (4) (2011) 676-688.

[64] S.M. Mccurry, et al., Measuring experiential avoidance: a preliminary test of a working model, Psychol. Rec. (54) (2004) 553-578.

[65] S.I. Saarni, et al., The health-related quality-of-life impact of chronic conditions varied with age in general population, J. Clin. Epidemiol. 60 (12) (2007) (1288. e11288. e11).

[66] W. Rief, et al., The relationship of modern health worries to depression, symptom reporting and quality of life in a general population survey, J. Psychosom. Res. 72 (4) (2012) 318-320.

[67] K. van Boven, et al., Do unexplained symptoms predict anxiety or depression? Tenyear data from a practice-based research network, Br. J. Gen. Pract. 61 (587) (2011) e316-e325.

[68] J. Bailer, et al., Evidence for overlap between idiopathic environmental intolerance and somatoform disorders, Psychosom. Med. 67 (6) (2005) 921-929.

[69] D. Eis, et al., The German multicentre study on multiple chemical sensitivity (MCS), Int. J. Hyg. Environ. Health 211 (5-6) (2008) 658-681.

[70] R. Runeson, D. Norbäck, Associations among sick building syndrome, psychosocial factors, and personality traits, Percept. Mot. Skills 100 (3) (2005) 747-759.

[71] F. Creed, et al., Depression and anxiety impair health-related quality of life and are associated with increased costs in general medical inpatient, Psychosomatics 43 (4) (2002) 302-309.

[72] V. Deary, T. Chalder, M. Sharpe, The cognitive behavioural model of medically unexplained symptoms: a theoretical and empirical review, Clin. Psychol. Rev. 27 (7) (2007) 781-797.

[73] M. Kleinstäuber, M. Witthöft, W. Hiller, Efficacy of short-term psychotherapy for multiple medically unexplained physical symptoms: a meta-analysis, Clin. Psychol. Rev. 31 (1) (2011) 146-160.

[74] G.E. Simon, et al., An international study of the relation between somatic symptoms and depression, N. Engl. J. Med. 341 (18) (1999) 1329-1335.

[75] M. Eliasen, et al., Somatic symptoms: prevalence, co-occurrence and associations with self-perceived health and limitations due to physical health-a Danish population-based study, PLoS One 11 (3) (2016) e0150664.

[76] M. Jansson-Fröjmark, A. Norell-Clarke, Cognitive behavioural therapy for insomnia in psychiatric disorders, Current Sleep Med. Rep. 2 (4) (2016) 233-240.

[77] M.T. Smith, M.I. Huang, R. Manber, Cognitive behavior therapy for chronic insomnia occurring within the context of medical and psychiatric disorders, Clin. Psychol. Rev. 25 (5) (2005) 559-592.

[78] J.M. Geiger-Brown, et al., Cognitive behavioral therapy in persons with comorbid insomnia: a meta-analysis, Sleep Med. Rev. 23 (2015) 54-67.

[79] R.M. Herr, et al., Effects and mediators of psychosocial work characteristics on somatic symptoms six years later: prospective findings from the Mannheim industrial cohort studies (MICS), J. Psychosom. Res. 98 (2017) 27-33.

[80] E. Finell, et al., The associations of indoor environment and psychosocial factors on the subjective evaluation of indoor air quality among lower secondary school students: a multilevel analysis, Indoor Air 27 (2) (2017) 329-337.

[81] E. Finell, T. Seppälä, Indoor air problems and experiences of injustice in the 
workplace: a quantitative and a qualitative study, Indoor Air 28 (1) (2018) 125-134.

[82] S. Selinheimo, et al., The association of psychological factors and healthcare use with the discrepancy between subjective and objective respiratory-health complaints in the general population, Psychol. Med. (2018) 1-11.

[83] L.J. Kirmayer, N. Sartorius, Cultural models and somatic syndromes, Psychosom.
Med. 69 (9) (2007) 832-840.

[84] M. Jylhä, What is self-rated health and why does it predict mortality? Towards a unified conceptual model, Soc. Sci. Med. 69 (3) (2009) 307-316.

[85] E.L. Idler, Y. Benyamini, Self-rated health and mortality: a review of twenty-seven community studies, J. Health Soc. Behav. (1997) 21-37. 